\title{
Herança da Resistência à Mancha-Bacteriana em Tomateiro*
}

\author{
Valácia L. da S. Lobo'**, Leonardo de B. Giordano² \& Carlos A. Lopes² \\ ${ }^{1}$ Departamento de Fitopatologia, Instituto de Ciências Biológicas, Universidade de Brasília, CEP 70919-900, Brasília, DF, \\ fax: (62) 533-2100, e-mail: valacia@ cnpaf.embrapa.br; ${ }^{2}$ Embrapa Hortaliças, Cx. Postal 218, CEP 70359-970, Brasília, \\ DF, e-mails: giordano@cnph.embrapa.br, clopes@cnph.embrapa.br
}

(Aceito para publicação em 01/12/2004)

Autor para correspondência: Valácia Lemes da Silva Lobo

SILVA-LOBO, V.L., GIORDANO, L.B. \& LOPES, C.A. Herança da resistência à mancha-bacteriana em tomateiro. Fitopatologia Brasileira 30:343-349. 2005.

\section{RESUMO}

A herança da resistência do tomateiro (Lycopersicon esculentum) à mancha-bacteriana (Xanthomonas campestris pv. vesicatoria, raça T2) foi estudada, em condições de campo, cruzando-se os genótipos resistentes 'Ohio 8245' e 'Hawaii 7998' com os genótipos suscetíveis 'CNPH 401-08' e 'CNPH 416.81.01.02', em um esquema dialélico desconsiderandose os recíprocos. Foram obtidas cinco famílias, cada uma constituída por seis gerações: Genitor ${ }_{1}$, Genitor ${ }_{2}, F_{1}, F_{2}$ e os retrocruzamentos $\left(\mathrm{RC}_{1}\right.$ e $\left.\mathrm{RC}_{2}\right)$. A família 'Ohio $8245 \times$ Hawaii 7998 ' apresentou menor média para severidade da doença, seguida por 'Hawaii $7998 \times$ CNPH 416.81.01.02' e 'Ohio $8245 \times$ CNPH 416.81.01.02', as quais, apresentaram maiores estimativas de herdabilidade e de predição de ganho por seleção. Em todas combinações, a herança da resistência genética à mancha-bacteriana foi do tipo quantitativa, com estimativa do número de genes variando de quatro a oito genes, conforme a família analisada. Foi observada segregação transgressiva nas famílias 'Ohio $8245 \times$ CNPH 401-08', 'Hawaii $7998 \times$ CNPH 401-08' e 'Hawaii $7998 \times$ CNPH 416.81.01.02'. Os efeitos gênicos foram do tipo aditivo para todas as famílias e os dados ajustados ao modelo aditivo-dominante, com o componente aditivo apresentando maior magnitude.

Palavras-chave adicionais: resistência horizontal, herdabilidade, Lycopersicon esculentum, Xanthomonas campestris pv. vesicatoria.

\begin{abstract}
Inheritance of resistance to bacterial spot in tomato

The inheritance of resistance to bacterial spot (Xanthomonas campestris pv. vesicatoria, race T2) in tomato (Lycopersicon esculentum) was investigated in a field trial. The genotypes 'Ohio 8245' and 'Hawaii 7998' (resistant), 'CNPH 401-08' and 'CNPH 416.81.01.02' (susceptible) were crossed in a diallel scheme without reciprocals. Each cross was labeled as one family, represented by six different generations: Parent ${ }_{1}$, Parent $, \mathrm{F}_{1}, \mathrm{~F}_{2}$ and Backcrosses to parents $\left(\mathrm{BC}_{1}\right.$ and $\left.\mathrm{BC}_{2}\right)$. The family 'Ohio $8245 \times$ Hawaii 7998' presented the lowest disease severity, followed by the family 'Hawaii $7998 \times \mathrm{CNPH}$ 416.81.01.02' and by the family 'Ohio $8245 \times$ CNPH 416.81 .01 .02 '. These last two families showed both higher broad and narrow sense inheritability estimates and the highest prediction of selection gain. The resistance was found to be quantitative, with four to eight genes involved, depending on the family. Transgressive segregation was observed in the 'Ohio $8245 \times$ CNPH 401-08', the 'Hawaii $7998 \times$ CNPH 401-08' and the 'Hawaii $7998 \times$ CNPH 416.81.01.02' families. The relevance of the additive effects was observed and for all the families the data fitted to additive-dominant model, with the additive component showing greater magnitude.
\end{abstract}

Additional keywords: horizontal resistance, inheritance, Lycopersicon esculentum, Xanthomonas campestris pv. vesicatoria.

\section{INTRODUÇÃO}

A mancha-bacteriana do tomateiro (Lycopersicon esculentum Mill), causada por Xanthomonas campestris pv. vesicatoria (Doidge) Dye (Xcv), é de ocorrência mundial e considerada uma das mais sérias doenças dessa cultura. Toda

\footnotetext{
* Parte da Tese de Doutorado do primeiro autor. Universidade de Brasília (2000).

** Endereço atual: Embrapa Arroz e Feijão, Cx. Postal 179, CEP 75375000, Santo Antônio de Goiás, GO.
}

a parte aérea da planta é suscetível à doença, sendo a infecção foliar e a subsequente desfolha o problema mais sério, pois reduz a produção e a qualidade dos frutos.

O controle da doença depende da combinação de práticas culturais, incluindo uso de sementes e plântulas livres do patógeno, limpeza da área, rotação de cultura, tratamento químico e uso de cultivares resistentes. A resistência genética é sem dúvida a melhor opção de controle. Entretanto, poucos genótipos com resistência a esta doença foram identificados. Em 1983, foi verificada resistência do 
tipo quantitativa em 'Hawaii 7998' à raça T1 de Xcv, o qual apresentou reação de hipersensibilidade (Scott \& Jones, 1989; Whalen et al., 1993; Wang et al., 1994).

Para a raça $\mathrm{T} 2$ de Xcv, primeiro relatada no Brasil em 1986 e hoje encontrada em todos os continentes, não se conhece o tipo de herança e nem fontes de resistência. Em estudos preliminares, 'Ohio 8245' apresentou níveis satisfatórios de resistência a essa raça (Silva-Lobo et al., 2000). A resistência à raça T3, descoberta na Flórida em 1991, foi observada em 'Hawaii 7981', uma linha irmã do 'Hawaii 7998'. A resistência nesta linha é controlada por um gene de dominância incompleta, Xv-3 e apresenta reação de hipersensibilidade (Scott et al., 1996).

Em programas de melhoramento visando resistência genética a doenças, é de fundamental importância o conhecimento da variabilidade do patógeno. A taxonomia e evolução entre os membros do gênero Xanthomonas associado ao tomate e ao pimentão (Capsicum annuum L.) tem sido objeto de discussão e controvérsia desde a sua descrição em 1921. Pesquisas sucessivas têm mostrado a existência de pelo menos dois grupos geneticamente diferentes pelas características fisiológicas, bioquímicas e de patogenicidade. $\mathrm{Em} \mathrm{Xcv}$, foram identificados três grupos, conforme as reações que provocam nas hospedeiras diferenciais: grupo tomate (XcvT); grupo pimentão (XcvP) e grupo tomatepimentão (XcvTP) (Minsavage et al., 1990). Dentro de cada grupo existem raças fisiológicas, das quais T1, T2 e T3 pertencem ao grupo tomate (Minsavage et al., 1990; Jones et al., 1995). Em 1994, Stall et al. (1994), utilizando diversos critérios, dividiram a espécie em dois grupos: A e B. Em seguida, Vauterin et al. (1995) com base na hibridização DNA-DNA e nos modelos de utilização de carbono dividiu Xcv em duas espécies: $X$. axonopodis pv. vesicatoria (grupo A - raça T1) e X. vesicatoria (grupo B - raça T2). Divisão esta, não aceita por Schaad et al. (2000), Young et al. (1996), que propuseram a classificação de $X$. campestris pv. vesicatoria para o grupo A e X. exitiosa (Valterin et al., 1995) para o grupo B. Recentemente, Jones et al.(2000), após realizar estudos, incluindo testes de patogenicidade atividade enzimática, marcadores genéticos, hibridização DNA-DNA e comparação de seqüências de RNA, concluiu que dentro do grupo das Xanthomonas patogênicas ao tomate e pimentão existem quatro grupos fenotípicos distintos, os quais apresentam três espécies genéticas diferentes, a saber: $X$. axonopodis pv.vesicatoria (grupos A e C), X. vesicatoria (grupo B - raça T2) e X. gardneri (ex Sutic 1957) Jones et al. 2000, sp. nov., nom rev., comb. nov. (grupo D).

Para o sucesso de um programa de melhoramento é necessário conhecer o tipo de herança, visando a escolha do método mais adequado a ser aplicado no desenvolvimento de novas cultivares. Considerando a prevalência da raça $\mathrm{T} 2$ no Brasil, para a qual não se tem conhecimento do tipo de herança da resistência à mancha-bacteriana, o presente estudo teve os objetivos: (a) estudar a herança da resistência à mancha-bacteriana, causada pela $X$. campestris pv. vesicatoria, raça $\mathrm{T} 2$ e determinar o modelo de ação gênica que permite a avaliação dos principais efeitos genéticos nos cruzamentos estudados; (b) estimar a herdabilidade no sentido amplo e restrito; a predição do ganho por seleção e o número de genes envolvidos na resistência.

\section{MATERIAL E MÉTODOS}

Para o estudo da herança da resistência, foram feitos cruzamentos entre os genitores resistentes 'Ohio 8245', 'Hawaii 7998' e os suscetíveis 'CNPH 401-8' e 'CNPH 416.81.01.02', previamente selecionados (Silva-Lobo et al., 2000), para obtenção das populações $F_{1}, F_{2}$ e os retrocruzamentos $\mathrm{RC}_{1}$ e $\mathrm{RC}_{2}$.

As famílias, composta de seis gerações $\left(\mathrm{P}_{1}, \mathrm{P}_{2}, \mathrm{~F}_{1}\right.$, $\mathrm{F}_{2}, \mathrm{RC}_{1}$ e $\mathrm{RC}_{2}$ ), foram avaliadas em campo. O delineamento experimental foi blocos ao acaso com três repetições, em parcelas subdivididas. As famílias constituíram as parcelas principais e as gerações dentro das famílias, as subparcelas. As plantas foram dispostas em linhas de $10 \mathrm{~m}$, num espaçamento de $0,5 \mathrm{~m}$ entre plantas e $1,0 \mathrm{~m}$ entre linhas. Em cada bloco, as subparcelas variaram de tamanho, de modo que cada geração não segregante (genitores e $F_{1}$ ) foi representada por uma linha com 20 plantas, os retrocruzamentos $\left(\mathrm{RC}_{1} \mathrm{e} \mathrm{RC}_{2}\right.$ ) por duas linhas (40 plantas) e a geração $\mathrm{F}_{2}$ por sete linhas (140 plantas). A inoculação foi feita aos 30 dias após o transplantio das mudas para o campo, pulverizando-se uma suspensão bacteriana $\left(10^{7} \mathrm{ufc} / \mathrm{ml}\right)$, do isolado CNPH 68 de Xcv, raça T2 proveniente da coleção bacteriana da Embrapa Hortaliças. A avaliação foi realizada 21 dias após a inoculação, mediante escala diagramática (Mello et al., 1997), considerando-se a severidade da doença em toda a planta. Os dados foram obtidos em plantas individuais e todas elas foram avaliadas.

As análises de variâncias, usadas para estimar médias e variâncias fenotípicas de cada população, foram realizadas para cada geração de cada família. E as análises de médias de gerações, pelo método dos quadrados mínimos ponderados, foram efetuadas em cada família, conforme Mather \& Jinks (1984). Os componentes de médias das seis gerações estudadas são dadas pelas equações abaixo:

$$
\begin{aligned}
& P_{1}=m+a+a a \\
& P_{2}=m-a+a a \\
& F_{1}=m+d+d d \\
& F_{2}=m+\frac{1}{2} d+\frac{1}{4} d d \\
& R C_{1}=m+\frac{1}{2} a+\frac{1}{2} d+\frac{1}{4} a a+\frac{1}{4} a d+\frac{1}{4} d d \\
& F_{1}=m-\frac{1}{2} a+\frac{1}{2} d+\frac{1}{4} a a-\frac{1}{4} a d+\frac{1}{4} d d
\end{aligned}
$$

O modelo ideal foi obtido pela fixação inicial de um modelo, contendo somente o componente de média $(\mathrm{m})$, incluindo os demais componentes de maneira seqüencial, conforme a contribuição dos mesmos para a redução dos quadrados médios residuais (Hallauer \& Miranda Filho, 1981). O ajuste dos modelos foi verificado por meio de um teste de escala conjunta, o qual consiste num teste de Qui- 
quadrado $\left(\chi^{2}\right)$ para os desvios das seis populações disponíveis, ponderados pelos seus respectivos pesos e segundo o número de graus de liberdade residuais. Uma vez alcançado o ajuste ( $\chi^{2}$ não significativo) nenhum outro componente foi adicionado.

A partir das variâncias fenotípicas de cada geração, estimou-se os componentes de variâncias genética e de ambiente para o caráter avaliado. No modelo aditivodominante de Mather \& Jinks (1984), tomando-se a geração $\mathrm{F}_{2}$ como população de referência e utilizando as notações de Falconer (1976), as estimativas dos componentes de variânciadas gerações utilizadas foram as seguintes: $\mathrm{VP}_{1}=$ $\mathrm{VE} ; \mathrm{VP}_{2}=\mathrm{VE} ; \mathrm{VF}_{1}=\mathrm{VE} ; \mathrm{VF}_{2}=\mathrm{VA}+\mathrm{VD}+\mathrm{VE} ; \mathrm{VRC}_{1}+$ $\mathrm{VRC}_{2}=\mathrm{VA}+2 \mathrm{VD}+2 \mathrm{VE}$; onde: VE é a estimativa da variância ambiental, VA a estimativa da variância genética aditiva e VD a estimativa da variância genética dominante. A partir dessas estimativas dos componentes de variâncias, estimou-se a herdabilidade no sentido amplo $\left(h^{2} a\right)$ e no sentido restrito $\left(\mathrm{h}^{2} \mathrm{r}\right)$, pelas fórmulas:

$$
\mathrm{h}^{2} \mathrm{a}(\%)=\frac{V A+V D}{V F_{2}} \times 100 \text { e } \mathrm{h}^{2} \mathrm{r}(\%)=\frac{V A}{V F_{2}} \times 100
$$

Os erros associados às estimativas das herdabilidades foram obtidos pelas equações fornecidas por Vello \& Vencovsky (1974).

Para a predição de ganhos por seleção, obtida pela análise das variâncias das gerações, foi considerada a seleção de $10 \%$ das melhores plantas da população $\mathrm{F}_{2} \mathrm{O}$ ganho esperado, considerando-se a seleção e a recombinação dos indivíduos superiores na população $\mathrm{F}_{2}$, foi estimado pela expressão:

$$
\Delta \mathrm{G}=\mathrm{DS} \mathrm{h}^{2} \mathrm{r} \text { e } \Delta \mathrm{G}(\%)=\frac{\Delta \mathrm{G} \times 100}{\overline{\mathrm{F}}_{2}}
$$

onde: $\mathrm{DS}=$ Diferencial de seleção $=\overline{\mathrm{X}}_{\mathrm{s}}{ }^{2} \overline{\mathrm{X}}_{0} ; \mathrm{X}_{\mathrm{s}}=$ média dos indivíduos selecionados em $\mathrm{F}_{2}, \mathrm{X}_{0}=$ média da população $\mathrm{F}_{2}, \mathrm{~h}^{2} \mathrm{r}=$ herdabilidade no sentido restrito.

O cálculo da estimativa do número de genes foi feito utilizando a fórmula citada por Cruz \& Regazzi (1997), que segue:

$$
n=\frac{\mathrm{R}^{2}\left(\frac{1+K^{2}}{2}\right)}{8 V G} \text { ou simplesmente, } n=\frac{\mathrm{R}^{2}}{8 V G},
$$

em que R é a amplitude total na população $\mathrm{F}_{2}, \mathrm{VG}$ a variância genotípica e $\mathrm{K}$ o grau médio de dominância (gmd), que é calculado pela fórmula:

$$
g m d=\mathrm{K}=\sqrt{\frac{2 V D}{V A}} .
$$

Todas as análises foram feitas usando-se o programa. SAS (SAS, 1985).

\section{RESULTADOS E DISCUSSÃO}

Observaram-se diferenças significativas no comportamento fenotípico, entre todos os cruzamentos e entre os genitores resistentes e suscetíveis, que se mostraram contrastantes em relação à severidade da doença, e as gerações descendentes $\left(\mathrm{F}_{1}, \mathrm{~F}_{2}, \mathrm{RC}_{1}\right.$ e $\left.\mathrm{RC}_{2}\right)$ do cruzamento entre esses genitores.

A família 'Ohio $8245 \times$ Hawaii 7998' apresentou menor média para severidade da mancha-bacteriana, seguida por 'Hawaii $7998 \times \mathrm{CNPH} 416.81 .01 .02$ ' e 'Ohio $8245 \times$ CNPH 416.81.01.02'. Com exceção do cruzamento entre os dois genitores resistentes ('Ohio 8245' e 'Hawaii 7998'), a menor severidade da doença foi observada nos cruzamentos em que se utilizou o progenitor suscetível ' $\mathrm{CNPH}$ 416.81.01.02'. Estas famílias foram também as que apresentaram as maiores estimativas de herdabilidade e de ganho por seleção.

Não existe no mercado brasileiro cultivar comercial com resistência à mancha-bacteriana, 'Ohio 8245' mostrou ser uma fonte promissora de resistência, com a vantagem de já ser utilizada comercialmente e apresentar frutos firmes, maturação uniforme, resistência à murcha-de-fusário, murcha-de-verticílio e antracnose (Berry et al., 1992).

Em todas as famílias, as populações segregantes $\left(\mathrm{RC}_{1}\right.$, $\mathrm{RC}_{2}$ e $\mathrm{F}_{2}$ ) apresentaram curva de distribuição contínua assimétrica, com a população $\mathrm{F}_{2}$ ocupando praticamente todas as classes (Figuras 1 e 2). Esta característica, aliada à sequiência de distribuição das médias das gerações, confirma a existência de um caráter quantitativo da herança da resistência à mancha-bacteriana, já verificado para a raça T1, utilizando-se outros genitores (Scott \& Jones, 1989; Whalen et al., 1993; Wang et al., 1994).

Nas famílias 'Ohio $8245 \times$ CNPH 401-08' (Figura 1) e 'Hawaii $7998 \times$ CNPH 401-08' (dados não apresentados) ocorreu segregação transgressiva na população segregante do $\mathrm{RC}_{1}$ e na família 'Hawaii $7998 \times \mathrm{CNPH}$ 416.81.01.02' a segregação transgressiva foi observada nas populações do $\mathrm{RC}_{1}$ $\mathrm{e}_{2}$ (Figura 2). Indicando a natureza poligênica da resistência e a possibilidade de selecionar melhores níveis de resistência à mancha-bacteriana nas populações segregantes.

A análise das estimativas dos parâmetros e seus desvios padrões, o teste de significância (t), o valor do Quiquadrado $\left(\chi^{2}\right)$ para o teste de ajustamento, o nível de probabilidade $(p)$ e o coeficiente de determinação $\left(R^{2}\right)$, mostram que os efeitos gênicos, sobre a 'severidade da mancha-bacteriana', foram do tipo aditivo para todas as famílias (Tabela 1), semelhante ao verificado para a raça T1 de Xcv em 'Hawaii 7998' (Scott \& Jones, 1989).

Os testes de verificação de ajustamento dos modelos apresentaram $\chi^{2}$ significativos para o modelo mais simples, aditivo-dominante, utilizaram-se, então, modelos com seis parâmetros, incluindo os efeitos epistáticos. Ainda assim, obteve-se $\chi^{2}$ significativos, optando-se pela transformação dos dados em raiz quadrada de $\mathrm{X}+0,5$ (Ramalho et al., 1993; Mather \& Jinks, 1984). Após a transformação dos dados, o modelo aditivo-dominante com três parâmetros, média (m), efeito aditivo (a) e efeito dos desvios de dominância (d), foi suficiente para explicar os cinco cruzamentos (Tabela 1). 

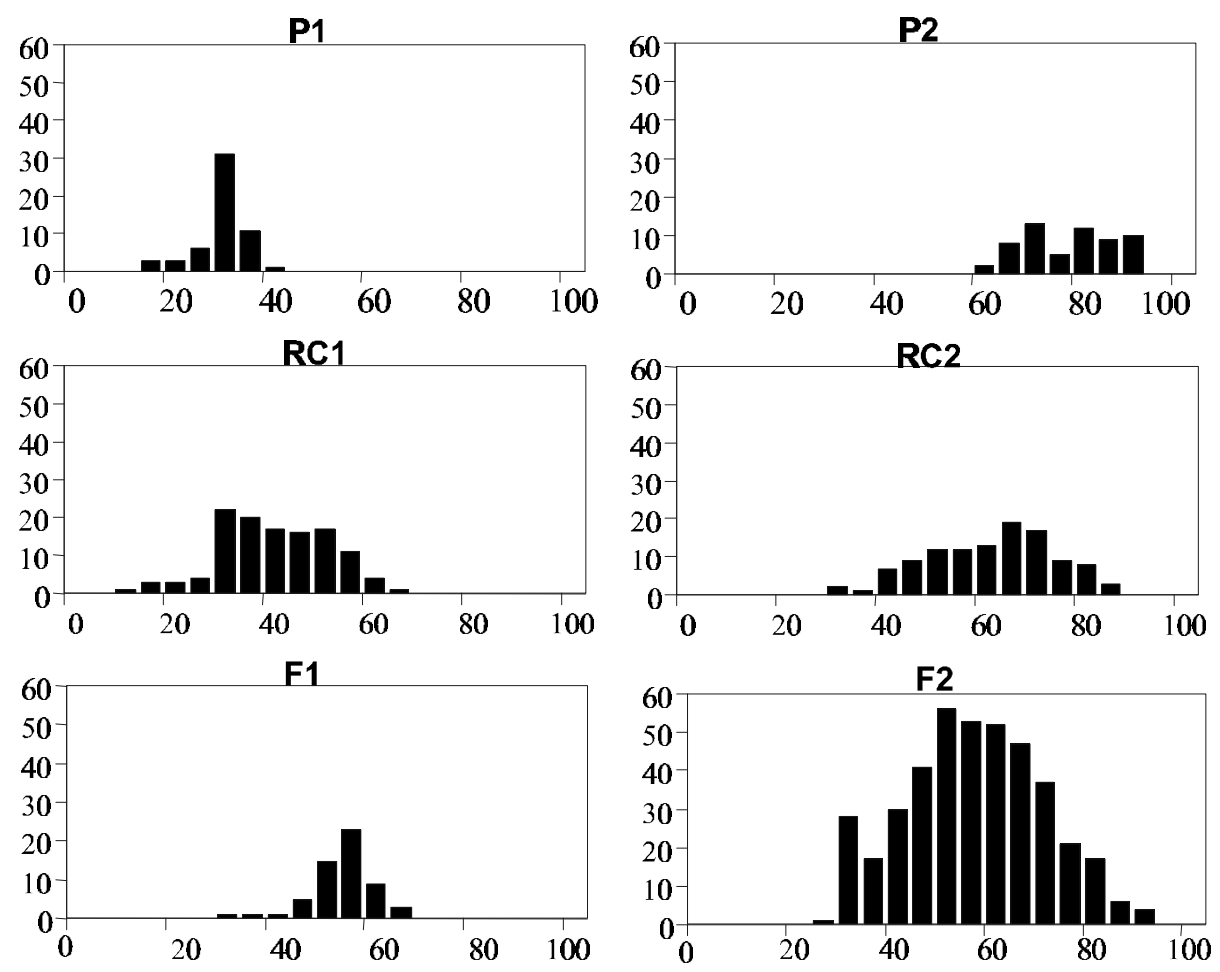

FIG. 1 - Distribuição de freqüência da porcentagem da área foliar com sintomas de mancha-bacteriana, causada por Xanthomonas campestris pv. vesicatoria das seis gerações da família 1, cruzamento entre os genótipos de tomateiro (Lycopersicon esculentum) 'Ohio 8245' $\left(\mathrm{P}_{1}\right) \mathrm{x}$ 'CNPH 401-08' $\left(\mathrm{P}_{2}\right)$.
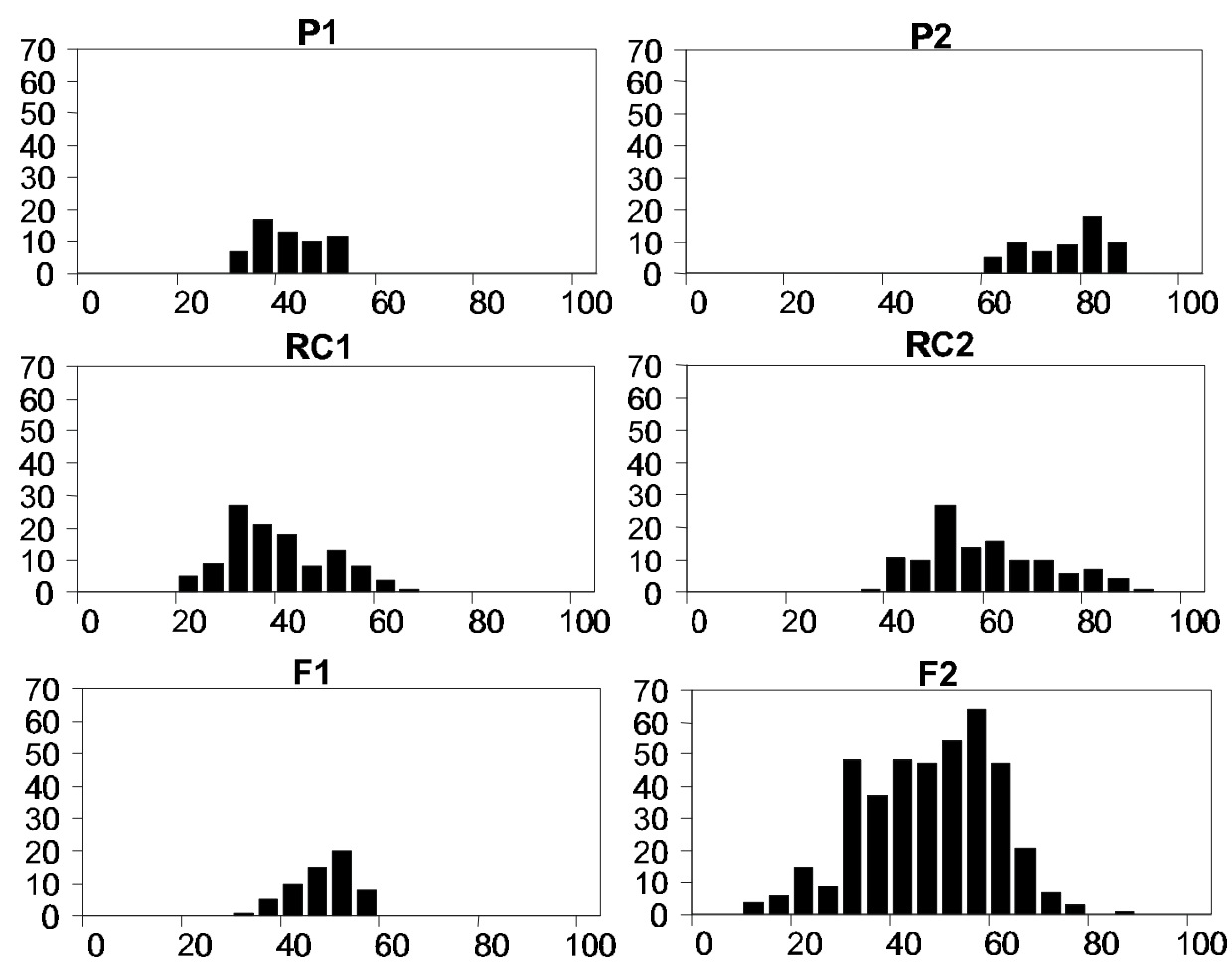

FIG. 2 - Distribuição de freqüência da porcentagem da área foliar com sintomas de mancha-bacteriana causada por Xanthomonas campestris pv. vesicatoria, das seis gerações da família 4, cruzamento entre os genótipos de tomateiro (Lycopersicon esculentum) 'Hawaii 7998' $\left(\mathrm{P}_{1}\right)$ x CNPH 416.81.01.02 $\left(\mathrm{P}_{2}\right)$. 
Em todas as famílias, os dados se ajustaram ao modelo aditivo-dominante, com o componente aditivo apresentando maior magnitude. Foi verificada significância do efeito aditivo (a), para resistência à mancha-bacteriana, em todos os cruzamentos e com registros de sua predominância absoluta sobre os respectivos efeitos de desvios de dominância (d). Isto é particularmente importante para o tomateiro, que é uma planta autógama; assim, as plantas homozigóticas serão os componentes regulares de qualquer população. A magnitude do efeito genético aditivo (a) indica o grau de probabilidades da resistência ser fixada nos indivíduos homozigóticos das gerações seguintes. A importância do efeito genético aditivo (a) tem sido amplamente discutida (Cruz \& Regazzi, 1997; Mather \& Jinks, 1984; Ramalho et al., 1993).

Por definição, o componente de efeito aditivo (a) nunca seria negativo, enquanto que o sinal do componente dos efeitos dos desvios de dominância (d) depende da direção predominante da dominância (Mather \& Jinks, 1984). A existência de componentes aditivos (a) com sinal negativo é explicada pelo fato de que nem sempre o progenitor $\mathrm{P}_{1}$, assim como seu respectivo retrocruzamento $\left(\mathrm{RC}_{1}\right)$, referese ao genótipo com maior expressão do caráter, que neste caso seria o genótipo de maior suscetibilidade à doença. Aqui o $\mathrm{P}_{1}$ com maior resistência é aquele que recebeu as menores notas e, consequentemente, menor média, portanto, menor severidade da mancha-bacteriana, por isso o sinal negativo do 'efeito aditivo - a', foi verificado em todas as famílias.

Ainda com relação aos modelos de ação gênica observou-se que os componentes de dominância foram positivos, ou seja, no sentido de maior suscetibilidade nas famílias 'Ohio $8245 \times$ CNPH 401-08', 'Ohio $8245 \times \mathrm{CNPH}$ 416.81.01.02' e 'Ohio $8245 \times$ Hawaii 7998'. Estes fatores prejudicam a seleção para a resistência em gerações segregantes porque possibilitam o descarte de indivíduos ou linhas potencialmente resistentes, mas em gerações endogâmicas mais avançadas estes efeitos tendem a desaparecer, indicando a conveniência de seleção mais rigorosa a partir de uma fase mais tardia de endogamia. Nas famílias em que se 'Hawaii 7998', o componente efeito de dominância foi negativo, ou seja, em direção à resistência. Nas famílias 'Ohio 8245 × CNPH 416.81.01.02' e 'Hawaii 7998 × CNPH 416.81.01.02', apesar da inclusão dos efeitos de dominância no modelo, os mesmos foram não significativos, seus valores foram duas vezes menores do que os seus desvios padrões, o que pode ser constatado também pelo teste de significância (Tabela 1).

Tomando como referência os valores dos melhores indivíduos (10\%), com menor severidade de manchabacteriana e selecionando-os na geração $\mathrm{F}_{2}$ de cada cruzamento, o cálculo da predição do ganho por seleção, indicou que a média dos indivíduos selecionados foi superior à média da população $\mathrm{F}_{2}$. Também o diferencial de seleção e a predição do ganho por seleção para o primeiro ciclo após a seleção apresentaram valores que permitem antever o êxito do material a ser melhorado, principalmente nos cruzamentos onde foram verificadas altas herdabilidades aliadas à predição do ganho por seleção também elevados. Destacaram-se neste aspecto as famílias 'Ohio $8245 \times \mathrm{CNPH}$

TABELA 1 - Estimativas de parâmetros genéticos e seus erros padrões, coeficientes de determinação $\mathrm{R}^{2}$ e de ajustamento dos modelos $\left(\chi^{2}\right.$ e P), obtidos por análise com médias de gerações nas famílias estudadas para a característica severidade de mancha-bacteriana do tomateiro (Lycopersicon esculentum) causada por Xanthomonas campestris pv. vesicatoria

\begin{tabular}{|c|c|c|c|c|c|c|}
\hline Cruzamento & Estimativa \pm erro padrão & Modelo & $\mathbf{t}$ & $\chi^{2}(\mathrm{gl})$ & $\mathbf{P}$ & $\mathbf{R}^{2}$ \\
\hline $\begin{array}{l}\text { Ohio } 8245 \\
\quad \text { X } \\
\text { CNPH } 401-8\end{array}$ & $\begin{array}{l}\mathrm{m}=7,1273 \pm 0,1264 \\
\mathbf{a}=-1,6330 \pm 0,1245 \\
d=0,1250 \pm 0,2339\end{array}$ & $\mathrm{Y}=\mathrm{m}+\mathbf{a}+\mathbf{d}$ & $\begin{array}{c}56,39 \\
13,12 \\
0,53^{*}\end{array}$ & $0,1163(3)$ & $>0,99$ & 0,98 \\
\hline $\begin{array}{l}\text { Ohio } 8245 \\
\quad \mathrm{X} \\
\text { CNPH 416.81.01.02 }\end{array}$ & $\begin{array}{l}\mathrm{m}=6,8305 \pm 0,0933 \\
a=-1,5390 \pm 0,0920 \\
d=0,5968 \pm 0,1728\end{array}$ & $\mathrm{Y}=\mathrm{m}+\mathbf{a}+\mathbf{d}$ & $\begin{array}{r}73,21 \\
16,73 \\
3,45\end{array}$ & $0,0634(3)$ & $>0,99$ & 0,98 \\
\hline $\begin{array}{l}\text { Hawaii } 7998 \\
\quad x \\
\text { CNPH 401-8 }\end{array}$ & $\begin{array}{l}\mathrm{m}=7,6420 \pm 0,1936 \\
\mathrm{a}=-1,0546 \pm 0,1908 \\
d=-0,2951 \pm 0,3586\end{array}$ & $\mathrm{Y}=\mathrm{m}+\mathbf{a}+\mathbf{d}$ & $\begin{array}{l}39,47 \\
5,53 \\
0,82 *\end{array}$ & $0,2732(3)$ & $>0,99$ & 0,91 \\
\hline $\begin{array}{l}\text { Hawaii } 7998 \\
\quad \mathrm{x} \\
\text { CNPH 416.81.01.02 }\end{array}$ & $\begin{array}{l}\mathrm{m}=7,3981 \pm 0,1802 \\
\mathbf{a}=-1,1993 \pm 0,1776 \\
\mathbf{d}=-0,8324 \pm 0,3338\end{array}$ & $\mathrm{Y}=\mathrm{m}+\mathbf{a}+\mathbf{d}$ & $\begin{array}{r}41,05 \\
6,75 \\
2,49\end{array}$ & $0,2367(3)$ & $>0,99$ & 0,94 \\
\hline $\begin{array}{l}\text { Ohio } 8245 \\
\quad x \\
\text { Hawaii } 7998\end{array}$ & $\begin{array}{r}m=5,9260 \pm 0,1621 \\
\mathbf{a}=-0,8582 \pm 0,1598 \\
d=0,7924 \pm 0,3002\end{array}$ & $\mathrm{Y}=\mathrm{m}+\mathbf{a}+\mathbf{d}$ & $\begin{array}{r}36,56 \\
5,37 \\
2,64\end{array}$ & $0,1916(3)$ & $>0,99$ & 0,92 \\
\hline
\end{tabular}

$[\mathrm{m}]=$ Componente de média; $[\mathrm{a}]=$ Componente aditivo; $[\mathrm{d}]=$ Componente dominante; * Efeito não significativo 
TABELA 2 - Estimativas dos componentes de variância, herdabilidades, número de genes, ganho e diferencial de seleção, média predita após primeiro ciclo de seleção e grau médio de dominância da resistência à mancha-bacteriana do tomateiro (Lycopersicon esculentum) causada por Xanthomonas campestris pv. vesicatoria

\begin{tabular}{|c|c|c|c|c|c|}
\hline \multirow[b]{2}{*}{$\begin{array}{l}\text { Parâmetro } \\
\text { Genético }\end{array}$} & \multicolumn{5}{|c|}{ Família } \\
\hline & $\begin{array}{c}\text { Ohio } 8245 \\
\quad \times \\
\text { CNPH 401-8 }\end{array}$ & $\begin{array}{c}\text { Ohio } 8245 \\
x \\
\text { CNPH } \\
\text { 416.81.01.02 }\end{array}$ & $\begin{array}{c}\text { Hawaii } 7998 \\
x \\
\text { CNPH 401-8 }\end{array}$ & $\begin{array}{c}\text { Hawaii } 7998 \\
X \\
\text { CNPH } \\
\text { 416.81.01.02 }\end{array}$ & $\begin{array}{c}\text { Ohio } 8245 \\
x \\
\text { Hawall } 7998\end{array}$ \\
\hline VF & 0,92 & 0,99 & 0,86 & 1,12 & 0,92 \\
\hline VG & 0,66 & 0,86 & 0,60 & 0,90 & 0,31 \\
\hline VA & 0,30 & 0,70 & 0,43 & 0,88 & 0,36 \\
\hline VD & 0,35 & 0,16 & 0,17 & 0,01 & -1 \\
\hline VE & 0,25 & 0,12 & 0,25 & 0,22 & 0,61 \\
\hline $\mathrm{N}$ & 8,08 & 3,53 & 4,00 & 5,15 & 7,79 \\
\hline GMD & 1,52 & 0,69 & 0,89 & 0,20 & -1 \\
\hline DS & 1,80 & 1,64 & 1,69 & 2,10 & 1,70 \\
\hline GS(\%) & 8,13 & 16,47 & 11,42 & 22,21 & 10,54 \\
\hline MPPCC & 6,82 & 5,87 & 6,64 & 5,05 & 5,70 \\
\hline$h^{2} \mathbf{a} \pm \operatorname{sh}^{2} \mathbf{a}$ & $72,28 \pm 0,06$ & $87,16 \pm \mathbf{0 , 0 5}$ & $70,42 \pm 0,06$ & $79,66 \pm 0,06$ & $33,54 \pm \mathbf{0 , 1 0}$ \\
\hline$h^{2} r \pm s^{2} r$ & $33,52 \pm 0,19$ & $70,50 \pm 0,15$ & $50,52 \pm 0,17$ & $78,04 \pm 0,14$ & $39,55 \pm 0,19$ \\
\hline
\end{tabular}

$\mathrm{VF}=$ Variância fenotípica (Variância $\mathrm{F}_{2}$ ); VG = Variância genotípica; $\mathrm{VA}=$ Variância aditiva; $\mathrm{VD}=$ Variância dominante; $\mathrm{VE}=$ Variância ambiental; $\mathrm{h}^{2} \mathrm{a}=$ Herdabilidade no sentido amplo; $h^{2} \mathrm{r}=$ Herdabilidade no sentido restrito; ${ }^{1}=$ Estimativas VD negativa; $\mathrm{N}=$ Número de genes; $\mathrm{GMD}=\mathrm{Grau}$ médio de dominância; DS = Diferencial de seleção; GS = Ganho de seleção; $\mathrm{Sh}^{2} \mathrm{a}=$ Erro associado às estimativas da herdabilidade no sentido amplo; $\mathrm{Sh}^{2} \mathrm{r}=$ Erro associado às estimativas da herdabilidade no sentido restrito; MPPCS = Média (porcentagem de área foliar com sintomas) predita para o primeiro ciclo após seleção

416.81.01.02' e 'Hawaii $7998 \times$ CNPH 416.81.01.02'.

As estimativas dos componentes de variância e das herdabilidades do caráter avaliado são apresentadas na Tabela 2. É importante ressaltar que a herdabilidade é uma propriedade do caráter, sendo válida apenas para a população e as condições ambientais a que os indivíduos foram submetidos (Ramalho et al., 1993; Cruz \& Regazzi, 1997).

Na família 'Ohio $8245 \times$ Hawaii 7998 ', as variâncias estimadas foram comparativamente pequenas, justificadas pela falta de divergência para esta característica entre os genitores envolvidos. As famílias 'Ohio $8245 \times \mathrm{CNPH}$ 416.81.01.02', 'Hawaii $7998 \times$ CNPH 401-08' e 'Hawaii $7998 \times$ CNPH 416.81.01.02' apresentaram estimativas de variância genética elevadas. Nestas famílias, o componente aditivo de variação foi sempre superior ao componente dominante e as herdabilidades no sentido restrito elevadas, sendo 70, 50 e 78\%, respectivamente. A família 'Ohio 8245 $\times$ CNPH 401-08' apresentou o componente dominante de variação superior ao componente aditivo, verificando-se uma estimativa da herdabilidade no sentido amplo de 72,3\% e no sentido restrito de $32,5 \%$, relativamente baixa em relação às famílias citadas anteriormente, o que se justifica pela variância aditiva pequena em relação à variância de dominância. Na família 'Ohio $8245 \times$ Hawaii 7998 ', o componente aditivo de variância foi positivo e não muito elevado, apresentando estimativa do componente de dominância negativa. Por isso, a herdabilidade, no sentido restrito foi relativamente elevada e mesmo superior à estimativa da herdabilidade no sentido amplo. Scott \& Jones (1989) também verificaram estimativas de componente de dominância negativa, o qual indica um efeito de dominância pequeno ou negligenciável e acreditam que isso se deve ao pequeno tamanho da população de retrocruzamento utilizada. Porém, neste estudo, trabalhou-se com uma população de 120 plantas para cada retrocruzamento, sendo o tamanho recomendado de 100 a 200 plantas (Ramalho et al., 1993).

As estimativas negativas podem ocorrer quando o componente de variância é muito pequeno. Outra causa provável, pode ter sido o não cumprimento dos pressupostos do método de Warner-Mather, onde se assume que as fontes de variação genética são exclusivamente de natureza aditivodominante e o componente de variância ambiental na geração $\mathrm{F}_{2}$ é igual à média dos componentes ambientais de variância nas gerações de retrocruzamento. E ainda, a possibilidade de erro resultante do julgamento humano, uma vez que a avaliação da doença foi feita visualmente, atribuindo-se nota na planta.

É normal a ocorrência de erros associados às estimativas quando se utiliza a variância. Normalmente estes erros são altos e as estimativas devem ser analisadas com os devidos cuidados (Vello \& Vencovsky, 1974; Ramalho et al., 1993). Os cálculos dos erros permitem antever a magnitude dos mesmos, que são dependentes do número de repetições e/ou observações dentro de cada progênie, além do valor da própria estimativa e da precisão experimental, sendo importante o cálculo dos mesmos quando da obtenção das estimativas. Neste estudo, estes erros foram baixos tanto para as estimativas das herdabilidades no sentido amplo, quanto no restrito (Tabela 2), indicando que as mesmas possuem confiabilidade e que houve uma boa precisão experimental. 
A estimativa do número de genes que governam a resistência variou de quatro a oito (Tabela 2). Estes valores não podem ser tomados de forma absoluta, mas sim como um indicativo do tipo de herança, se é de natureza mono, oligo ou poligênica. A estimativa do número de genes observada neste estudo confirma o caráter quantitativo da herança da resistência, igualmente ao verificado a raça $\mathrm{T} 1$ do mesmo patógeno por Scott \& Jones 1989; Whalen et al., 1993; Wang et al., 1994. Estes valores estimados do número de genes dão um indicativo de que cada cruzamento tem sua particularidade, dependendo dos genótipos utilizados nos cruzamentos e dos fatores bióticos e abióticos ao qual são submetidos.

É importante salientar que estudos de herança para outros componentes do complexo "mancha-bacteriana do tomateiro" devem ser realizados visando à busca de genótipos com resistência estável à doença.

\section{REFERÊNCIAS BIBLIOGRÁFICAS}

BERRY, S.Z., GOULD, W.A. \& WIESE, K.L. 'Ohio 8245' varietal protection applied for pedigree. Tomato Genetics Cooperative 42:73. 1992. (Report).

CRUZ, C.D. \& REGAZZI, A.J. Modelos biométricos aplicados ao melhoramento genético. $2^{\text {a }}$ edição. Viçosa. Editora da UFV. 1997.

FALCONER, D.S. Introduction to quantitative genetics. $2^{\text {nd }}$ ed. London. Logman. 1976.

HALLAUER, A.R. \& MIRANDA FILHO, J.B. Quantitative genetics in maize breeding. Ames. Iowa State University Press. 1981.

JONES, J.B., STALL, R.E., SCOTT, J.W., SOMODI, G.C. \& BOUZAR, H. A third tomato race of Xanthomonas campestris pv. vesicatoria. Plant Disease 79:395-398. 1995.

JONES, J.B, BOUZAR, H., STALL, R.E., ALMIRA, E.C., ROBERTS, P.D., BOWEN, B.W., SUDBERRY, J., STRICKLER, P.M. \& CHUN, J. Systematic analysis of xanthomonads (Xanthomonas spp.) associated with pepper and tomato lesions. International Journal of Systematic and Evolutionary Microbiology 50: 1211-1219. 2000

MATHER, S.K. \& JINKS, J.L. Introdução à genética biométrica. Ribeirão Preto: Sociedade Brasileira de Genética, 1984.

MELlO, S.C.M., TAKATSU, A. \& LOPES, C.A. Escala diagramática para avaliação da mancha-bacteriana do tomateiro. Fitopatologia Brasileira 22:447-448. 1997.

MINSAVAGE, G.V., DALHLBECK, D., WHALEN, M., KEARNEY, B., BONAS, U., STASKAWICZ, B.J. \& STALL, R.E. Gene-for-gene relationship specifying disease resitance in
Xanthomonas campestris pv. vesicatoria-pepper interactions. Molecular Plant-Microbe Interactions 3:41-47.1990.

RAMALHO, M.A.P., SANTOS, J.B. \& ZIMMERMANN, M.J. de O. Genética quantitativa em plantas autógamas; aplicações ao melhoramento do feijoeiro. Goiânia: Editora da UFG. 1993.

SAS USER'S GUIDE: Statistics. 5 ed. North Carolina: SAS Institute. 1985.

SCHAAD, N.M., VIDAVER, A.K., LACY, G.H., RUDOLPH, K. \& JONES, J.B. Evaluation of proposed amended names of several Pseudomonads and Xanthomonads and recomendations. Phytopathology 90:208-213. 2000.

SCOTT, J.W. \& JONES, J.B. Inheritance of resistance to foliar bacterial spot of tomato incited by Xanthomonas campestris pv. vesicatoria. Journal of the American Society Horticultural Science 114:111-114. 1989.

SCOTT, J.W., STALL, R.E., JONES, J.B. \& SOMODI, G.C. A single gene controls the hypersensitive response of Hawaii 7998 to race 3 (T3) of the bacterial spot pathogen. Tomato Genetics Cooperative 46:23. 1996 (Report).

SILVA-LOBO, V.L. Herança e componentes da resistência à mancha-bacteriana (Xanthomonas campestris pv. vesicatoria, raça T2) em tomateiro. (Tese de Doutorado). Brasília. Universidade de Brasília. 2000

STALL, R.E., BEUALIEU, C., EGEL, D., HODGE, N.C., LEITE, R.P., MINSAVAGE, G.V., BOUZAR, H., JONES, J.B., ALVAREZ, A.M. \& BENEDICT, A.A. Two genetically diverse groups of strains are included in Xanthomonas campestris pv. vesicatoria. International Journal of Systematic Bacteriology 44:47-53. 1994.

VAUTERIN, L., HOSTE, B., KERSTERS, K. \& SWINGS, J. Reclassification of Xanthomonas. International Journal of Systematic Bacteriology 45:472-489. 1995.

VELLO, N.A. \& VENCOVSKY, R. Erros associados às estimativas de variâncias e coeficientes de herdabilidades. Relatório científico do Instituto de Genética. Piracicaba:ESALQ. 1974. pp.238-348.

WANG, J.F., JONES, J.B., SCOTT, J.W. \& STALL, R.E. Several genes in Lycopersicon esculentum control hypersensitivity to Xanthomonas campestris pv. vesicatoria. Phytopathology 84:702706. 1994.

WHALEN, M.C., WANG, J.F., CARLAND, FM., HEISKELL, M.E., DAHLBECK, D., MINSAVAGE, G.V., JONES, J.B., SCOTT, J.W., STALL, R.E. \& STASKAWICZ, B.J. Avirulence gene avrRxv from Xanthomonas campestris pv. vesicatoria on tomato line Hawaii 7998. Molecular Plant-Microbe Interactions 6:616-627. 1993.

YOUNG, J.M., SADDLER, G.S., TAKIKAWA, Y., DE BOER, S.H., VAUTERIN, L., GARDAN, L., GVOZDYAK, R.I. \& STEAD, D.E. Names of plant pathogenic bacteria 1864-1995. Review of Plant Pathology 75:721-763. 1996. 